\title{
Contents of Opticheskiu Zhurnal (Journal of Optical Technology), vol. 76, nos. 2 and 3, 2009
}

PACS numbers: 01.10.Cr

DOI: $10.1134 / \mathrm{S} 0030400 \mathrm{X} 09030254$

The following papers will be published in the February issue of Opticheskiu Zhurnal (Journal of Optical Technology), vol. 76, no. 2, 2009.

Physical Optics. Suppression of the Wavelength Dependence of the Diffraction Efficiency of Two-Order Relief-Phase Diffraction Structures (G.I. Greŭsukh, E.G. Ezhov, and S.A. Stepanov).

Iconics: The Science of Images. Reconstruction of Images Allowing for Their Structure (N.N. Krasil'nikov); Algorithms Optimal by Neumann-Pirson Criterion for Assessment of White Gaussian Pulsed Noise in Images (T.A. Samoǔlin).

Optical Instrumentation and Technology. Some Problems of the Development of Videospectral Aerial Survey (A.V. Markov and B.V Shilin); Miniature Fourier-Transform Spectrometer AOST for Space Research (O.I. Korablev, A.V. Grigor'ev, F. Monmesan, B.E. Moshkin, D.V. Patsaev, V.S. Makarov, S.V. Maksimenko, K.V. Grechnev, V.I. Kotlov, L.V. Zasova, A.V. Shakun, A.A. Fedorova, A.I. Terent'ev, A.P. Ékonomov, I.V. Khatuntsev, B.S. Mă̌orov, Yu.V. Nikol'skiü, I.A. Maslov, A.B. Gvozdev, and R.O. Kuz'min);

The Use of Thermally Induced Nanosized Surface Deformations for Attenuation of Pulsed Light Fluxes (N.V. Prudnikov, V.V. Chesnokov, D.V. Chesnokov, S.L. Shergin, and V.B. Shlishevskiǔ); High-Resolution Spectrograph of the 6-Meter BTA Telescope (V.E. Panchuk, V.G. Klochkova, M.V. Yushkin, and I.D. Naŭdenov); A Setup for Photometric Measurements of the Crown of a Plant (S.A. Rakut'ko).

Optical Materials Science and Technology. Thickness Uniformity of Films Deposited on Rotating Substrates (E.N. Kotlikov, V.A. Ivanov, V.N. Prokashev, and A.N. Tropin); Formation of a Specified Linear Distribution of the Refractive Index in Glass by Silver Diffusion through a Mask (B.I. Yudin); Development of a Technique for Growing Large-Size Optical Leucosapphire Crystals at Vavilov State Optical Institute (M.I. Musatov).

Practical Manufacturing Problems. Photolithographic Techniques in the Production of Optical Scales (Graticules) (D.Yu. Kruchinin).

The following papers will be published in the March issue of Opticheskil Zhurnal (Journal of Optical Technology), vol. 76, no. 3, 2009.

Physical Optics. Electronic Absorption Spectra of Complexes of Organic Compounds with Energy-
Degenerate Molecular Orbitals (K.F. Krivul'ko and A.P. Klishchenko); Determination of the Effective Radiating Volume in Emission Spectroscopy of an Extended Medium (A.A. Shepelenko).

Laser Physics and Technology. Titanium-Sapphire Laser Pumped by Second-Harmonic Radiation of a Longitudinally Diode-Pumped Neodymium Laser (G.I. Ryabtsev, M.V. Bogdanovich, A.I. Enzhievskiŭ, L.L. Teplyashin, A.G. Ryabtsev, M.A. Shchemelev, A.V. Pozhidaev, and N.V. Kondratyuk).

Computation, Design, and Manufacture of Optical Systems. A Method for Measuring Wavefront Deformations up to $\lambda / 8$ Induced by a Large-Aperture Afocal System (D.S. Gavrilov, A.G. Kakshin, and E.A. Loboda).

Iconics: The Science of Images. Optimal Estimation of the Position of Zero-Centered Pulsed Gaussian Noise in Images (E.A. Samoullin); Procedure for the Development of Mathematical Models of Automated On-Board Optoelectronic Systems (Yu.M. Belyakov, A.I. Karpov, V.A. Krenev, and D.A. Molin).

Holography. The Use of Digital Holographic Microscopy for Study of Thin Transparent Films (D.N. Tishko, T.V. Tishko, and V.P. Titar').

Optical Instrumentation and Technology. Metrological Problems of Surface Temperature Measuring by Noncontact IR Pyrometry (E.K. Galanov, and M.K. Filatov); Comparative Analysis of the Stability of Nondetunable Scanners (A.Ya. Gebgart).

Optical Materials Science and Technology. New Light-Scattering Glass-Ceramics SOO-U6 and SOO-I8 (O.S. Dymshits, A.A. Zhilin, V.A. Parfinskiŭ, A.Yu. Polushkin, and A.V. Shashkin); Correction of the Spectral Characteristics of Cutoff Filters (E.N. Kotlikov and A.N. Tropin); Stability Criterion of the Spectral Characteristics of Multilayer Interference Coatings (E.N. Kotlikov and A.N. Tropin); Study of the Orientation Order of Polystyrene Molecular Chains in the Surface Layers of Thin Films by the Oblique Polarized Beam Method (A.E. Grishchenko, N.A. Mikhaĭlova, A.I. Kononov, T.V. Rudakova, and A.B. Mel'nikov); Ellipsometric Study of the Specific Features of $\mathrm{HfO}_{2}$ Film Buildup on Optical Glass (V.A. Odarich).

Compiled by L.V. Enushevskaya Translated by S. Belov 